\title{
El videoling: uso educativo del vídeo en la enseñanza de la gramática $^{*}$
}

\section{Videoling: video as an educational purpose in grammar teaching}

\author{
Alícia Martí Climent \\ Universitat de València \\ Alicia.Marti@uv.es \\ ORCID ID: https://orcid.org/0000-0003-1005-5630
}

Pilar Garcia Vidal

Universitat de València

Pilar.Garcia-Vidal @uv.es

ORCID ID: https://orcid.org/0000-0001-6336-3149

DOI: $10.17398 / 1988-8430.33 .75$

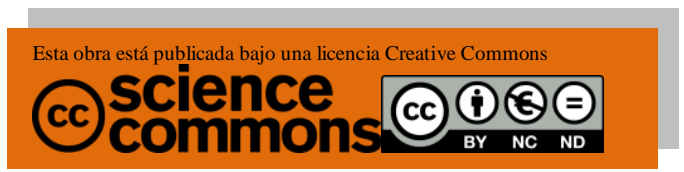

Fecha de recepción: 31/03/2020

Fecha de aceptación: 05/05/2020

Martí Climent, A., y Garcia Vidal, P. (2021). El videoling: uso educativo del vídeo en la enseñanza de la gramática. Tejuelo, 33, 75-102.

Doi: https://doi.org/10.17398/1988-8430.33.75

\footnotetext{
* Este estudio forma parte del Proyecto de Innovación Educativa titulado "TIC, TAC, TAP. Proyectos de lengua y literatura" (UV-SFPIE_RMD18-841879), coordinado por Martí y desarrollado durante el curso 2018-2019.
} 
Resumen: Presentamos una experiencia de trabajo por proyectos de lengua con TIC llevada a cabo en el Máster Universitario en Profesor/a de Educación Secundaria de la Universitat de València durante los últimos cinco años. El objetivo fundamental es que el futuro profesorado aprenda a elaborar materiales didácticos sobre gramática con TIC para aplicarlos en las aulas de secundaria y de bachillerato. El enfoque metodológico planteado consiste en el desarrollo de un proyecto de trabajo de lengua con la incorporación de las TIC sobre uno de los contenidos gramaticales del currículo de secundaria y bachillerato del área de Lengua $\mathrm{y}$ Literatura aplicado a un nivel o etapa educativa. Se trata de proyectos realizados por nuestros estudiantes, con la incorporación de recursos TIC para su elaboración, que han sido adecuados para trabajar algunos aspectos gramaticales del currículo de secundaria. En este estudio presentamos el proyecto llamado videoling, es decir, cápsulas audiovisuales sobre cuestiones lingüísticas difundidas en Youtube. Con el uso de las TIC en los proyectos de trabajo sobre gramática se pretende reforzar el aprendizaje lingüístico del alumnado y ofrecer recursos para incentivar el autoaprendizaje.

Palabras clave: gramática; TIC; aprendizaje basado en proyectos (ABP); enseñanza secundaria; vídeo educativo.
Abstract: This research is about a task based experience working ICT on language projects carried out in the Master's Degree in Secondary Education at the University of Valencia during last five years. The main aim is that future teachers learn to elaborate educational materials on grammar with ICT to apply in Secondary Education and Baccalaureate. The methodological approach deals with a language taskbased learning stated, introducing ICT tools in a grammatical content in Secondary Education and Baccalaureate in language and literature in an educational stage. A sample of projects carried out by our students is going to be introduced, dealing with ICT tools for implementing some grammatical aspects taken from the Secondary Education curriculum. They have been adapted to work on some grammatical aspects of the secondary curriculum. In this research a project named videoling is introduced, based on audiovisual capsules dealing with linguistics issues which have been disseminated on Youtube. With the use of ICT in grammar projects it is intended to reinforce the linguistic learning of the students and offer resources to encourage self-learning.

Keywords: grammar; ICT; ProjectBased Learning (PBL); Secondary Education; educational video. 


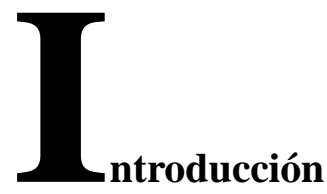

Presentamos un análisis sobre la utilización del vídeo como refuerzo para trabajar la lengua mediante la realización de proyectos de gramática con TIC llevado a cabo en el Máster Universitario en Profesor/a de Educación Secundaria de la Universitat de València desde el curso 2011-12 hasta el 2017-18, concretamente en la materia «Complementos para la formación disciplinar de la especialidad de lengua y literatura catalana».

En investigaciones anteriores se apuntaba la escasa formación en TIC que demuestra la mayoría de los estudiantes del máster y la necesidad de incorporar las TIC en la formación universitaria y especialmente en la formación inicial de docentes (Martí y Garcia Vidal, 2014; Garcia Vidal y Martí, 2017). Castañeda, Esteve y Adell (2018) proponen una competencia docente integral en el mundo digital para la enseñanza básica. Desde nuestro punto de vista, el perfil del futuro profesorado de Secundaria debe contemplar competencias 
específicas para mejorar el proceso de adquisición y desarrollo de competencias con el apoyo de las TIC.

En principio, hay que advertir que no se trata de utilizar las TIC para hacer lo mismo pero de forma más rápida y cómoda, sino de hacer cosas diferentes para poder poner en marcha procesos de aprendizaje y de enseñanza que no serían posibles con la ausencia de las TIC (Coll, 2008). En este sentido proponemos trabajar la competencia digital de una manera adecuada para que favorezca la competencia comunicativa integral en el entorno multimedia. Teniendo en cuenta la investigación de Garcia Vidal (2018) sobre cómo se aprenden las lenguas desde la perspectiva del alumnado de secundaria, encontramos los siguientes aspectos positivos en el uso de las TIC para aprender lenguas: los recursos audiovisuales, el trabajo con el ordenador, la posibilidad de presentar los trabajos con programas que les facilitan y mejoran el diseño, y la utilidad de la imagen para favorecer la comprensión y la producción de textos.

Además, en estudios anteriores (Garcia Vidal y Martí, 2012, 2013, 2017; Martí y Garcia Vidal, 2014, 2016) se han señalado las ventajas de la incorporación de las TIC en el trabajo académico ya que facilitan el trabajo compartido y su difusión en las redes sociales; potencian diferentes habilidades lingüísticas, la creatividad y la originalidad; promueven la inclusión digital en las aulas de manera que se favorezca la atención a la diversidad, y refuerzan el aprendizaje individual, entre otros.

Tal como afirman Sánchez-Caballé, Larraz y González-Martínez (2019), desde la Universidad se debe garantizar el desarrollo de la competencia digital ofreciendo situaciones de aprendizaje que den respuestas creativas, viables y justificadas que evidencien el grado de adquisición de esta competencia.

En este artículo inicialmente revisaremos diversas investigaciones sobre la utilización de las TIC en la etapa de secundaria para centrarnos después en el uso del vídeo como un instrumento para 
el aprendizaje lingüístico y la adquisición de la competencia digital. Posteriormente, comentaremos nuestra propuesta didáctica en la que nos planteamos trabajar la corrección lingüística. Finalmente, presentaremos el proyecto del videoling, que tiene como objetivo resolver dudas gramaticales; el análisis realizado sobre algunos productos elaborados por el alumnado del Máster de Secundaria; los resultados conseguidos, y las posibles implicaciones didácticas que conlleva.

\section{El uso de las TIC en el aula de secundaria}

Las investigaciones de Colás y Pablos (2004) sobre la implantación de las TIC en los centros de primaria y secundaria apuntan hacia la insuficiente formación del profesorado en TIC y la falta de referencias para llevar a cabo aplicaciones educativas con las TIC.

Según el estudio de Barberá y Fuentes (2012) sobre la integración de las TIC en los procesos de enseñanza-aprendizaje, los estudiantes consideran que se hace un buen uso, pero hay problemas de infraestructura tecnológica (pocos recursos TIC en los centros educativos o funcionamiento defectuoso) y también falta de motivación o de formación del profesorado en el uso de las TIC en la enseñanza.

Ahora bien, si hay que formar al futuro profesorado para trabajar las competencias, como se establece en la ley de educación, conviene que la adquisición de la competencia digital se incorpore de una manera evidente. Entendemos la competencia digital, a partir de la definición de Cabero y Barroso (2016, p. 246), como los valores, creencias, conocimientos, capacidades y actitudes para utilizar adecuadamente las tecnologías, incluyendo tanto los ordenadores como los programas y herramientas que permiten la investigación, el acceso, la organización y la utilización de la información con el fin de construir conocimiento.

Por otra parte, estudios como los de Carlino (2013) sobre alfabetización académica permiten conocer las dificultades del 
alumnado para interpretar y producir textos académicos. En este aspecto, el alumnado podría incorporar las TIC como instrumentos de trabajo para compartir diferentes tipos de documentos, usar vídeos educativos como recurso formativo e interactivo, hacer uso de los enlaces, elaborar y publicar noticias, emplear la prensa digital como recurso y estrategia para aprender a aprender, seleccionar y procesar la información, etc. Se trata de aprovechar el potencial que ofrecen las TIC para mejorar la escritura. Así pues, su incorporación en el trabajo en el aula permite considerar las formas linguísticas desde una perspectiva más funcional, ya que en muchos casos plantea el uso de la lengua en situaciones de comunicación, con unos géneros discursivos que requieren la interacción entre el alumnado, con el fin de coordinar y decidir los recursos que emplearán considerando quién será el receptor, puesto que se trata de proyectos que presuponen una difusión en la red. Facilitar el trabajo colaborativo, la coordinación y la posibilidad de compartir es otra ventaja importante que incorporan las TIC, según señalan los mismos alumnos. Como dice Castelló (2009), es importante favorecer la posibilidad de una escritura colaborativa y que los estudiantes interactúen y reflexionen con las herramientas apropiadas.

\section{Consideramos con Méndez Garrido y Delgado García (2016)} que las TIC ofrecen numerosas posibilidades para mejorar el aprendizaje del alumnado y, además, suponen un elemento innovador para el profesorado. A pesar de ello, las TIC no han contado con el apoyo mayoritario de los docentes, lo que conlleva dificultades de coordinación e implementación en las aulas. Conviven varias opciones metodológicas difíciles de conciliar al contraponerse una enseñanza tradicional, fundamentada casi exclusivamente en el uso del libro de texto en las clases, a otra más innovadora, que incorpora las TIC pero que todavía está en proceso de consolidación y aceptación entre la mayoría del profesorado. Tal como indica Salmerón (2019), aunque la relación entre tecnología y aprendizaje puede conllevar efectos negativos, hay que fomentar un uso educativo eficaz de las TIC con el fin de aprovechar sus potencialidades y limitar sus perjuicios. 
Las TIC son ahora más accesibles, lo que supone una gran ventaja para trabajar con los estudiantes, que cada vez las conocen y las incorporan más en su actividad diaria. Estas circunstancias se pueden aprovechar para que los estudiantes empleen estas herramientas con solvencia, como un medio para mejorar su trabajo académico $\mathrm{y}$, en este caso, el aprendizaje de la lengua.

\section{Uso educativo del vídeo}

Tradicionalmente, el vídeo como recurso didáctico ha estado muy presente en contextos educativos y ha tenido muchas funciones como transmitir información, motivar o presentar contenidos, por lo tanto, debería ser parte fundamental de la educación mediática de nuestro alumnado, tal como señala García García (2014). Recientemente se ha convertido en una herramienta básica para la aplicación de la metodología denominada Flipped classroom o clase invertida, que consiste en utilizar el vídeo para presentar al alumnado los contenidos de la materia que luego se trabajan en clase. Según Sánchez, Ruíz y Gómez (2016), el vídeo también puede utilizarse como instrumento de evaluación y para la alfabetización mediática ya que el alumnado se ha convertido cada vez más en "prosumidor" de medios, es decir, creador de sus propios medios audiovisuales.

Muchos jóvenes utilizan YouTube como medio de comunicación y plataforma de expresión sobre temas variados. Al respecto, trabajos como el de Scolari (2018) nos muestran cómo investigaciones con estudiantes de diferentes contextos revelan que YouTube es uno de los medios con mayor presencia en la cotidianeidad de los jóvenes y está ganando relevancia como fuente de conocimiento académico para los estudiantes, mediante videotutoriales y creando un nuevo espacio para suplir vacíos que los educadores no pueden asumir. Los YouTubers se han convertido en influencers y han creado una narración transmedia que llega a diferentes aspectos de la cultura juvenil. Este formato narrativo suele ser simple, reconocible y pragmático pero también ha supuesto el desarrollo de competencias digitales como la edición de 
vídeo, el diseño y la planificación de una narración audiovisual, y la consideración de valores éticos en la difusión de la información. La difusión en las redes sociales de los trabajos realizados supone también que es necesario tener más cuidado en su elaboración, revisión y presentación, ya que tienen un carácter más público.

Además, encontramos estudios como los de Salmerón y Llorens (2018, citado en Salmerón, 2019) que demuestran las ventajas de utilizar el vídeo para la instrucción de búsqueda autorregulada de información en Wikipedia en estudiantes de secundaria. En este trabajo se confirmó que los estudiantes pasaban de realizar una lectura digital rápida a una más pausada que les permitía comprender mejor el contenido.

De hecho, el vídeo permite diferentes usos en la enseñanza, como explica Cabero (2007). Los más habituales son la transmisión de contenidos y la motivación de los estudiantes hacia un tema. En este proyecto, el vídeo se utiliza como instrumento de conocimiento producido por el alumnado, lo que nos permite, como señalan Cabero y Barroso (2016), el desarrollo de la última categoría de la taxonomía de Bloom adaptada para la era digital (Churches, 2009): crear. Todo proceso de aprendizaje parte de las habilidades de pensamiento básicas (recordar y comprender) pero hay que asegurar que el estudiante alcanza las habilidades intermedias (aplicar y analizar) y llega a las habilidades de pensamiento complejo (evaluar y crear). El objetivo final es que el alumnado cree materiales didácticos, concretamente un vídeo para resolver dudas lingüísticas y mejorar la corrección lingüística; por tanto, deben idear, diseñar, filmar, producir y publicar.

La incorporación del vídeo en el trabajo académico posibilita incidir en aspectos clave para contribuir a un aprendizaje significativo. Además, la introducción de este recurso supone una alfabetización en y para la cultura digital y conlleva un aumento de posibilidades de participación (Lara, 2009). Se desarrolla fundamentalmente la competencia mediática que incluye la digital, la comunicativa, la lingüística y la audiovisual. También se potencia la creatividad y la 
originalidad, que enriquece cualquier material didáctico, y se refuerza el aprendizaje individual ya que permite más autonomía para trabajar y acceder más fácilmente a la información.

En este estudio nos centraremos en el análisis del videoling, proyecto en que se emplea el vídeo para trabajar la lengua, y analizaremos las posibles aportaciones de este recurso en el aprendizaje lingüístico y en la adquisición de la competencia digital del alumnado.

\section{El aprendizaje lingüístico en la etapa de secundaria}

La didáctica de la lengua constituye un campo de conocimiento que tiene como finalidad el complejo proceso de enseñar y de aprender lenguas con el objetivo de mejorar las prácticas y adecuarlas a las situaciones cambiantes en las que esta actividad se desarrolla (Camps, Guasch, Ruiz Bikandi, 2010). El profesorado de lengua, pues, ha de crear las situaciones adecuadas en el aula y emplear las metodologías más convenientes para que el alumnado alcance una competencia comunicativa.

Hay un acuerdo unánime, según señala Ferrer (2012), sobre el objetivo de la educación lingüística en la etapa de secundaria: el desarrollo de la competencia comunicativa del alumnado, entendida como la capacidad para interactuar mediante discursos coherentes, cohesionados y adecuados a la finalidad y a la situación de comunicación en que se inscriben.

De acuerdo con el Marco Europeo Común de Referencia para las Lenguas (MCER) (2002), los alumnos deben tener una competencia comunicativa más específicamente relacionada con la lengua. Se trata de la competencia gramatical, que se puede definir como el conocimiento de los recursos gramaticales de una lengua y la capacidad de utilizarlos. Un aspecto cualitativo del uso de la lengua es el mantenimiento de un consistente control gramatical sobre un repertorio lingüístico complejo. 
Hay que tener en cuenta también, como apunta Guasch (2011), los últimos cambios que se han producido en los contextos educativos debido a la diversidad lingüística, la introducción de las tecnologías y las expectativas respecto a la formación linguística los estudiantes. Paralelamente, el panorama de la enseñanza de la lengua ha ido transformándose de manera significativa. Si nos fijamos en la corrección lingüística, que es un ejercicio habitual entre el profesorado de lengua, no siempre produce los resultados esperables ya que los errores del alumnado continúan repitiéndose a pesar de haber insistido en trabajar la normativa un curso detrás de otro. El profesorado de lengua debe ir, por tanto, más allá de la mera "alfabetización", que hace referencia al conocimiento establecido, para tener en cuenta el concepto de "literacidad" en el sentido de conocimiento procesal, tal como remarcan Ríos y Salvador (2008), que integra hablar, escuchar, el pensamiento crítico con la lectura y la escritura, la diversidad cultural y lingüística, y la influencia de las tecnologías.

Puede afirmarse que estar alfabetizado actualmente supone ser capaz de actuar con competencia en cada una de las situaciones sociales donde se requiere el uso de la lengua. La didáctica constructivista ha dado un giro en cuanto al tratamiento del error y su gestión. Guasch (1997) apunta que el error es un instrumento de aprendizaje lingüístico si la conciencia de su existencia desencadena una serie de acciones para repararlo, de manera que lleve al usuario a cuestionarse sus conocimientos lingüísticos.

Por otro lado, la multimodalidad se ha presentado como un fenómeno caracterizador de la cultura escrita. Podemos afirmar, con Bombini y Martínez (2018), que las imágenes siempre han estado formando parte de ésta. Los materiales educativos con las tecnologías y sus potencialidades han transformado las formas de leer y escribir. Desarrollar cierta creatividad artística es el desafío principal de la presencia de las tecnologías en la escuela. 


\section{El videoling en la enseñanza de la gramática}

El objetivo fundamental que nos proponemos es que el futuro profesorado aprenda a elaborar materiales didácticos sobre gramática con TIC para aplicarlos en las aulas de secundaria y de bachillerato, con la intención de reforzar el aprendizaje lingüístico del alumnado, crear recursos para incentivar el autoaprendizaje, aprovechar la riqueza de materiales que nos ofrece la red y favorecer su aplicación didáctica.

Es por ello que este estudio plantea el aprendizaje lingüístico con el apoyo de las tecnologías, concretamente del uso educativo del vídeo, a partir del tratamiento del error en la enseñanza de la gramática. Por una parte, el proyecto posibilita trabajar cualquier aspecto gramatical, desde la ortografía y la pronunciación de la lengua hasta la morfología y la sintaxis, entre otros. Por otra, tenemos el tratamiento del error.

En este trabajo planteamos que el alumnado se encuentre en situaciones de comunicación reales y realice, de manera interactiva, actividades que propicien la reflexión metalingüística como fuente de aprendizaje. Tal como afirman Fernández, González y Pérez (2018), el alumnado vive en escenarios comunicativos propios y el aula no puede quedar al margen de esta realidad.

La creación de una producción audiovisual sobre cuestiones lingüísticas puede favorecer la reflexión del alumnado sobre los errores más habituales y las partes de la gramática que pueden ser más difíciles de aprender. Además, si se trata de un proyecto colaborativo y tiene una finalidad comunicativa, como es el caso de la creación de un vídeo sobre cuestiones de lengua (videoling), puede resultar un material didáctico eficaz para ayudar al alumnado a aprender de una manera activa convirtiéndolo en protagonista de su propio aprendizaje. Resulta, por tanto, conveniente aprovechar la gran potencialidad que ofrecen los materiales didácticos digitales para desarrollar las habilidades lingüísticas y comunicativas. 


\section{1. Metodología}

Quisiéramos comprobar la efectividad didáctica del vídeo con el análisis de un proyecto didáctico audiovisual que consideramos fácilmente aplicable para trabajar la lengua de manera eficaz con herramientas TIC. Nos centraremos en el uso del vídeo como medio para reforzar el estudio de la gramática. Con este objetivo presentamos el proyecto consistente en la realización de un vídeo creativo, que hemos llamado videoling, sobre las cuestiones de lengua que plantean más dificultades para el alumnado. El videoling es una cápsula audiovisual que presenta prácticas dramatizadas en torno a alguna cuestión lingüística.

Con los videoling nos proponemos los siguientes objetivos: resolver dudas lingüísticas habituales de los estudiantes, mejorar la corrección lingüística, utilizar las TIC para reforzar el aprendizaje lingüístico y ofrecer recursos para incentivar el autoaprendizaje.

Para llevar a cabo esta propuesta seguiremos la metodología del Aprendizaje basado en proyectos (ABP) ya que consideramos, con Rodríguez Gonzalo (2008), que los proyectos de trabajo han demostrado ser una forma de planificación eficaz y un instrumento de observación e investigación por parte del profesorado que ofrece muchas posibilidades para la innovación educativa. De acuerdo con Trujillo (2012), la enseñanza basada en proyectos o tareas integradas supone hoy la mejor garantía didáctica para una contribución eficaz al desarrollo de las competencias básicas y el aprendizaje de los contenidos del currículo. Además, el uso intensivo de las TIC para el desarrollo de los proyectos favorece la capacidad de motivación del alumnado, el acceso a fuentes de información y las posibilidades para la gestión del propio proyecto, el manejo de datos y la realización del producto.

El enfoque metodológico planteado consiste en el desarrollo de un proyecto de trabajo de lengua, siguiendo a Camps (1996), con la incorporación de las TIC. Los estudiantes se constituyen en grupos de 4 
o 5 personas y seleccionan uno de los contenidos gramaticales del currículo de secundaria y bachillerato del área de Lengua y Literatura aplicado a un nivel o en una etapa educativa. La secuencia de actividades sigue la propuesta presentada por Kilpatrick en 1918 (Zabala, 1995, citado en Rodríguez Gonzalo, 2008, p. 29), cuando definió el método de proyectos como un plan de trabajo con el objetivo de realizar algo que despierte el propio interés. Según esta secuencia, para la realización del videoling se desarrollan las siguientes fases:

\section{Tabla 1}

Fases de realización del proyecto videoling

\begin{tabular}{ll}
\hline \multicolumn{1}{c}{ Fases } & \multicolumn{1}{c}{ Descripción } \\
\hline Propuesta & Proyección de modelos de vídeos \\
\hline Planificación & $\begin{array}{l}\text { Establecer la duda lingüística a trabajar y planificar la } \\
\text { ejecución del videoling }\end{array}$ \\
\hline Elaboración & Realización del videoling \\
\hline $\begin{array}{l}\text { Presentación y difusión } \\
\text { del trabajo }\end{array}$ & Exhibición en clase del videoling y difusión en YouTube \\
\hline
\end{tabular}

Fuente: elaboración propia

Tras la proyección de modelos de vídeos para trabajar diferentes cuestiones lingüísticas, el profesorado plantea al alumnado la realización por grupos de un videoling. En primer lugar, el docente indica a cada grupo que tienen que pensar en una duda lingüística que tengan frecuentemente; en segundo lugar, una vez cada grupo ha acordado tratar una duda con el profesor/a, se planifica la realización del videoling; $\mathrm{y}$, en tercer lugar, se muestra en la clase el producto audiovisual realizado para trabajar la cuestión lingüística propuesta. Finalmente, se difunde a través de Youtube.

De esta forma, el grupo clase con el profesor/a decidirá cuáles son las cuestiones gramaticales que necesitan reforzarse especialmente. El alumnado se organizará en grupos para producir diferentes videolings que tratan de aclarar las principales dudas lingüísticas. Conseguiremos así que el alumnado acuerde con el profesorado cómo puede resolver los principales problemas de lengua con los que se enfrenta y mejorar 
su práctica lingüística, a nivel oral y escrito, mediante recursos audiovisuales.

Respecto a los criterios para evaluar los vídeos educativos presentados en este estudio, hemos tomado como referencia los indicados por Ballesteros-Regaña (2013, p. 177-178), que considera que hay que tener en cuenta las siguientes cuestiones: a quien va dirigido, cuando se utilizará, que se pretende, como se usará, la predisposición del alumnado y el profesorado hacia el vídeo como recurso didáctico, el contexto de enseñanza-aprendizaje en el que se incluye el vídeo, las diferencias cognitivas entre el alumnado, la participación e intervención de alumnado y profesorado, las propiedades técnicas, las características semánticas expresivas, la versatilidad y la interacción con otros recursos TIC.

\section{2. Muestra de videoling}

En este artículo presentamos y analizamos una muestra representativa de los trabajos realizados. Un ejemplo es el videoling sobre el uso correcto del pronombre y conjunción "que", elaborado por nuestros estudiantes, en el cual, mediante ejemplos dramatizados, se explican las normas lingüísticas que rigen su uso y se proponen ejercicios para utilizarlo correctamente. De manera similar, en otros vídeos los estudiantes explican cuestiones relativas a norma y uso, como la utilización del apóstrofe, los verbos "ser" y "estar" o los pronoms febles en catalán. 


\section{Figura 1}

Imagen del videoling sobre el uso de QUE

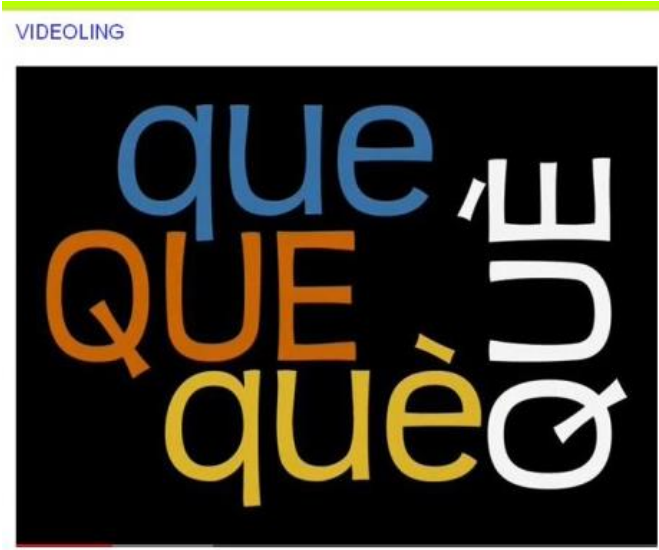

Fuente: elaboración propia

Otra posibilidad para trabajar cuestiones lingüísticas en formato audiovisual es la creación de un noticiario didáctico. En el caso que presentamos, el objetivo es trabajar la fonética de algunos tipos de consonantes. El informativo académico creado consta de tres partes, en las que los alumnos han de grabar una serie de vídeos simulando que son reporteros cubriendo una información de actualidad. Así, los periodistas se desplazan a diferentes lugares para contar noticias que suponen tener que pronunciar correctamente las consonantes palatales, las alveolares, y las bilabiales y labiodentales. Se emplean juegos de palabras y trabalenguas que evidencian la pronunciación correcta de estas consonantes. 


\section{Figura 2}

Informativo académico

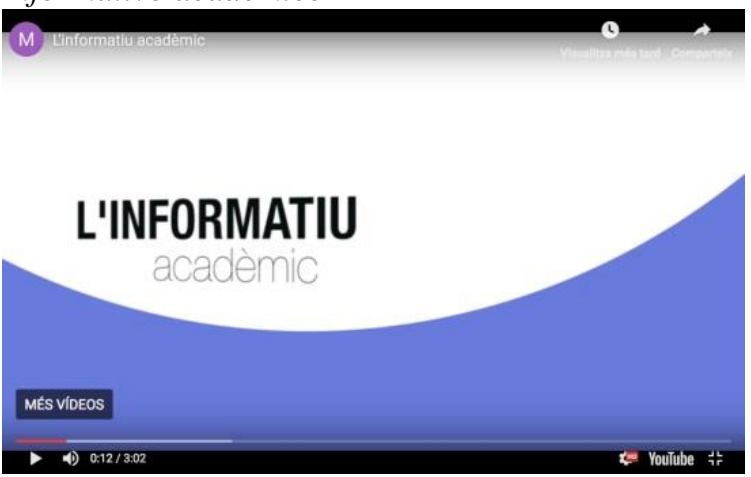

Fuente: elaboración propia

Un caso diferente de videoling es la realización de un «noticiario humorístico» para trabajar los refranes y las frases hechas mediante el lenguaje periodístico. El vídeo, creado por los estudiantes del Máster de Secundaria, comienza con una presentación, donde se definen las cuestiones lingüísticas que se van a trabajar: las diferencias y coincidencias entre los refranes y las frases hechas. Después, comienza el noticiario, en el que dos periodistas presentan noticias de actualidad y terminan con un refrán o frase hecha que las ilustra y el vídeo de la noticia, donde se hace una parodia con intención humorística de lo comentado previamente.

\section{Figura 3}

\section{Noticiario humorístico}

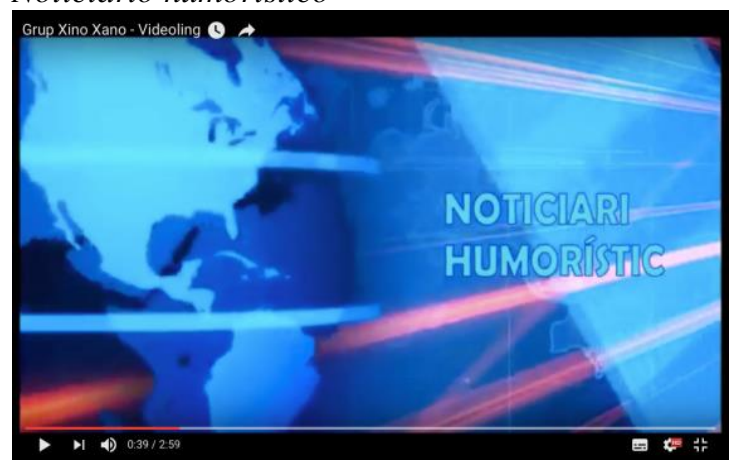

Fuente: elaboración propia 


\section{Análisis y resultados}

En el análisis del videoling debemos tener en cuenta la efectividad de la producción de textos orales con el apoyo de las TIC, utilizando las estrategias de expresión oral y los elementos no verbales adecuados a la situación comunicativa y al objetivo propuesto, aplicando las propiedades textuales y el léxico adecuado al nivel educativo, para practicar aprendizajes lingüísticos y estructurar el pensamiento.

A partir de los criterios de análisis planteados anteriormente, hemos elaborado una tabla para realizar el análisis de los videolings seleccionados, indicando en qué medida los proyectos audiovisuales realizados cumplen las características que se consideran propias de los videos educativos para aprender gramática:

\section{Tabla 2}

Criterios de análisis para los videoling

\begin{tabular}{ll}
\hline Objetivos & 1. Resolver dudas y mejorar la competencia lingüística \\
& 2. Utilizar las TIC para reforzar el aprendizaje lingüístico usando \\
imágenes y sonidos \\
3. Potenciar la creatividad para incentivar el aprendizaje de la \\
lengua
\end{tabular}




\begin{tabular}{|c|c|}
\hline & $\begin{array}{l}\text { 9. Actuar de forma crítica y responsable en el uso de las TIC } \\
\text { 10. Autonomía e iniciativa personal } \\
\text { 11. Constancia y esfuerzo para conseguir los objetivos y seguir } \\
\text { las actividades }\end{array}$ \\
\hline Contenidos & $\begin{array}{l}\text { 1. Cualquier cuestión del Bloque 3. Conocimiento de la lengua } \\
\text { 2. Géneros dialogados de la comunicación oral, formales y } \\
\text { espontáneos, de los medios de comunicación social y de los } \\
\text { ámbitos profesional y administrativo } \\
\text { 3. Características básicas de textos de los ámbitos periodísticos, } \\
\text { profesional y administrativo: función comunicativa, } \\
\text { estructura, marcas lingüísticas, recursos verbales y no } \\
\text { verbales } \\
\text { 4. Creación y producción sencilla de vídeo } \\
\text { 5. Almacenamiento de la información digital en la red }\end{array}$ \\
\hline $\begin{array}{l}\text { Habilidades } \\
\text { lingüísticas }\end{array}$ & $\begin{array}{l}\text { 1. Expresión oral } \\
\text { 2. Expresión escrita } \\
\text { 3. Comprensión oral } \\
\text { 4. Interacción oral } \\
\end{array}$ \\
\hline $\begin{array}{l}\text { Aspectos } \\
\text { gramaticales }\end{array}$ & $\begin{array}{l}\text { Cualquier cuestión del Bloque 3. Conocimiento de la lengua del } \\
\text { currículo del área de lengua y literatura de Secundaria }\end{array}$ \\
\hline $\begin{array}{l}\text { Corrección } \\
\text { lingüística }\end{array}$ & $\begin{array}{l}\text { 1. Aplicación correcta de las normas ortográficas de la lengua } \\
\text { 2. Uso adecuado de las propiedades textuales (adecuación, } \\
\text { coherencia, cohesión y corrección) } \\
\text { 3. Utilización del registro estándar }\end{array}$ \\
\hline $\begin{array}{l}\text { Elementos de } \\
\text { expresión oral } \\
\text { no verbales, } \\
\text { corporales y } \\
\text { paralingüísticos }\end{array}$ & $\begin{array}{l}\text { 1. Gesticulación } \\
\text { 2. Mirada } \\
\text { 3. Tono } \\
\text { 4. Dicción } \\
\text { 5. Espacio }\end{array}$ \\
\hline $\begin{array}{l}\text { Tipología } \\
\text { textual }\end{array}$ & $\begin{array}{l}\text { 1. Expositiva } \\
\text { 2. Argumentativa } \\
\text { 3. Narrativa } \\
\text { 4. Instructiva }\end{array}$ \\
\hline Género textual & $\begin{array}{l}\text { 1. Noticia } \\
\text { 2. Exposición } \\
\text { 3. Reportaje } \\
\text { 4. Anuncio publicitario }\end{array}$ \\
\hline $\begin{array}{l}\text { Aspectos } \\
\text { técnicos- } \\
\text { estéticos }\end{array}$ & $\begin{array}{l}\text { 1. Grabación } \\
\text { 2. Edición } \\
\text { 3. Imagen } \\
\text { 4. Audio } \\
\text { 5. Título } \\
\text { 6. Créditos }\end{array}$ \\
\hline
\end{tabular}




\begin{tabular}{ll}
\hline Creatividad & Originalidad \\
\hline $\begin{array}{l}\text { Duración del } \\
\text { vídeo }\end{array}$ & 2 o 3 minutos \\
\hline $\begin{array}{l}\text { Transversalida } \\
\mathrm{d}\end{array}$ & $\begin{array}{l}\text { 1. Igualdad } \\
\text { 2. Utilización de un lenguaje inclusivo }\end{array}$ \\
\hline Versatilidad & Adaptabilidad a otros cursos o etapas educativas \\
\hline Recursos TIC & $\begin{array}{l}\text { 1. Creación de un canal de YouTube para incrustar los vídeos } \\
\text { creados }\end{array}$ \\
& $\begin{array}{l}\text { 2. Cámara de vídeo o móvil } \\
\text { 3. Programas de edición de vídeo }\end{array}$ \\
\hline
\end{tabular}

Fuente: elaboración propia

El análisis realizado sobre los videolings comentados anteriormente es de tipo cualitativo a partir de las categorías planteadas, lo que nos permitirá evaluar la calidad del videoling como objeto de aprendizaje lingüístico. En la siguiente tabla podemos observar que en la elaboración de los tres videolings presentados se han seguido mayoritariamente los criterios establecidos para dar cuenta de la calidad de los videos educativos para aprender gramática.

\section{Tabla 3}

Análisis de los videoling: Que què, Informativo académico y Noticiario humorístico

\begin{tabular}{llll}
\hline Videoling & Que què & $\begin{array}{l}\text { Informativo } \\
\text { académico }\end{array}$ & $\begin{array}{c}\text { Noticiario } \\
\text { humorístico }\end{array}$ \\
\hline Objetivos & $1,2,4$ & $1,2,4$ & $1,2,3,4$ \\
\hline Competencias & $1,2,3,4$ & $1,2,3,4$ & $1,2,3,4$ \\
\hline Habilidades & $1,2,3,4$, & $1,2,3,4$, & $1,2,3,4$, \\
& $5,6,7,8,9,10,11$ & $5,6,7,8,9,10,11$ & $5,6,7,8,9,10,11$ \\
\hline Contenidos & $1,2,3,4,5$ & $1,2,3,4,5$ & $1,2,3,4,5$ \\
\hline Habilidades & $1,2,3,4$ & $1,2,3,4$ & $1,2,3,4$ \\
lingüísticas & & & Refranes y frases \\
\hline Aspectos & Diferencia entre la & Fonética de las & \\
gramaticales & conjunción, & consonantes & \\
& pronombre, & palatales, las & \\
& adverbio y adjetivo & alveolares, las & \\
& QUE, y el & bilabiales y & \\
pronombre con & labiodentales & \\
& acento diacrítico & & $1,2,3$ \\
\hline $\begin{array}{l}\text { Corrección } \\
\text { lingüística }\end{array}$ & QUÈ & & \\
\hline
\end{tabular}




\begin{tabular}{|c|c|c|c|}
\hline $\begin{array}{l}\text { Elementos de } \\
\text { expresión oral no } \\
\text { verbales, corporales } \\
\text { y paralingüísticos }\end{array}$ & $1,2,3,4,5$ & $1,2,3,4,5$ & $1,2,3,4,5$ \\
\hline Tipología textual & $1,2,3,4$ & 1,3 & $1,2,3,4$ \\
\hline Género textual & 2 & 1 & 1,2 \\
\hline $\begin{array}{l}\text { Aspectos técnicos- } \\
\text { estéticos }\end{array}$ & $1,2,3,4,5$ & $1,2,3,4,5$ & $1,2,3,4,5$ \\
\hline Creatividad & $\begin{array}{l}\text { Bastante original: } \\
\text { intercala } \\
\text { explicación } \\
\text { gramatical con } \\
\text { dramatización e } \\
\text { imágenes que la } \\
\text { ilustran }\end{array}$ & $\begin{array}{l}\text { Bastante original: } \\
\text { elabora noticias para } \\
\text { usar determinadas } \\
\text { consonantes } \\
\text { acompañadas de } \\
\text { imágenes de noticias } \\
\text { reales que las } \\
\text { ilustran }\end{array}$ & $\begin{array}{l}\text { Bastante original: } \\
\text { parodia noticias } \\
\text { inventadas que } \\
\text { ilustran los } \\
\text { refranes y frases } \\
\text { hechas destacados }\end{array}$ \\
\hline Duración del vídeo & 5 minutos & 3 minutos & 3 minutos \\
\hline Transversalidad & No & No & No \\
\hline Versatilidad & Sí & Sí & Sí \\
\hline Recursos TIC & $1,2,3$ & $1,2,3$ & $1,2,3$ \\
\hline
\end{tabular}

Fuente: elaboración propia

En el análisis de los videolings observamos que se trabajan los objetivos, competencias, destrezas, contenidos, habilidades previstas y los aspectos gramaticales correspondientes a los contenidos curriculares. También se han presentado producciones con una buena expresión linguística, tanto oral como escrita, acompañada por elementos de expresión oral no verbales, corporales y paralingüísticos adecuados al texto correspondiente. Se han empleado diferentes tipologías textuales, según los géneros presentados. Se han cuidado los aspectos técnicos con una buena producción audiovisual en la que se han editado los vídeos con música, imágenes, sonido, títulos y créditos de forma correcta.

En cuanto a la creatividad, todos los videos son originales y se han intentado crear situaciones nuevas para trabajar la normativa gramatical a partir de los géneros periodísticos y en un contexto que conecte con referentes conocidos del alumnado. En todos los vídeos se ha empleado el humor como un elemento fundamental para motivar al receptor. 
La duración de las producciones es corta y responde al objetivo propuesto, ya que es preferible que los vídeos educativos sean breves y sirvan mejor para introducir o completar el tema que se quiere trabajar, dentro del contexto de la clase, con sesiones que suelen ser de 55 minutos.

Un aspecto que no se ha incluido en ningún vídeo y que consideramos que sería una aportación de interés en un recurso educativo es la transversalidad. Sobre todo en un proyecto de lengua convendría que se pusiera de relieve también la importancia del lenguaje inclusivo.

Respecto a la versatilidad, los vídeos que hemos visto son adaptables a cualquier curso de secundaria o bachillerato ya que las cuestiones de lengua que se presentan se pueden reforzar con más o menos profundidad según el nivel o necesidades del alumnado. Finalmente, los recursos TIC utilizados son los apropiados para la edición y la difusión en las redes sociales.

Además de la función didáctica del videoling, que ha permitido desarrollar la competencia comunicativa del alumnado, los vídeos han cumplido una función motivadora $\mathrm{y}$ han potenciado el trabajo cooperativo. Este recurso supone un instrumento para la alfabetización mediática ya que el alumnado se convierte en productor de mensajes audiovisuales, desarrolla la creatividad, la innovación y los conocimientos sobre el uso de herramientas tecnológicas.

\section{Implicaciones didácticas}

El videoling es un recurso didáctico que puede contribuir a la enseñanza de la lengua proporcionando nuevos contextos comunicativos, mediante producciones audiovisuales y su difusión en redes sociales, que implican diferentes estilos de escritura, una revisión 
y presentación de textos más cuidada y una nueva alfabetización mediática.

Una ventaja importante que aportan las TIC, según indican los alumnos a partir de su evaluación de los proyectos realizados, es favorecer el trabajo colaborativo, la coordinación y la facilidad para compartir. Por lo tanto, encontramos también una repercusión positiva para su aprendizaje ya que, como afirma Castelló (2014), es importante ofrecer la posibilidad al alumnado de una escritura colaborativa de manera que puedan interactuar y reflexionar con las herramientas apropiadas.

De acuerdo, pues, con los resultados positivos obtenidos, después del análisis de los videolings, proponemos su uso en la clase de lengua teniendo en cuenta que se puede aumentar su potencial didáctico incluyendo contenidos transversales e incidiendo en la utilización del lenguaje inclusivo. Además, se tendría que tener en cuenta también la atención a la diversidad y aprovechar las posibilidades del audiovisual para facilitar al máximo la participación activa de todo el alumnado, tanto en la realización del vídeo como en el trabajo sobre las dudas lingüísticas que se presenten. Como afirman Castejón, López y Selga (2016), la incorporación de la tecnología puede potenciar la capacidad del alumnado para resolver problemas y aumentar las posibilidades de aprendizaje. Mediante el videoling se puede favorecer el aprendizaje de la gramática a partir de las preguntes, las dudas y los errores lingüísticos que se plantean. Permite, pues, ampliar la competencia de comunicación linguiística y la creatividad del alumnado siempre que se utilice de forma equilibrada e inclusiva, eliminando las posibles barreras para el aprendizaje y la participación. Por ello, es importante optar por una tecnología ágil, sencilla y gratuita, que favorezca la autonomía y la disponibilidad a los usuarios.

La incorporación de las TIC en el trabajo académico debe conllevar la posibilidad de incidir en aspectos clave para contribuir a un aprendizaje significativo. Con este objetivo, empleamos todas aquellas TIC que nos permiten trabajar nuevos géneros de escritura, además de 
los habituales, y desarrollar las competencias básicas entre el alumnado, fundamentalmente la competencia mediática que incluye la digital, la comunicativa, la lingüística y la audiovisual.

Además, el trabajo por proyectos con TIC ha supuesto la posibilidad de profundizar en las ventajas e inconvenientes de estas herramientas en los procesos de enseñanza y aprendizaje de la gramática; experimentar diferentes metodologías didácticas, aumentar la interacción entre profesorado y alumnado, la accesibilidad de la información y atender la diversidad del alumnado. El uso de diferentes recursos TIC facilita una planificación didáctica eficaz y motivadora, potencia la creatividad y la originalidad, refuerza el aprendizaje individual y permite la difusión de propuestas de trabajo innovadoras.

\section{Conclusiones}

El alumnado cada vez tiene un mayor grado de conocimiento de recursos TIC, lo que posibilita implementarlos en la docencia para mejorar la planificación didáctica en el área de lengua y literatura en cuanto a la organización de las ideas, la presentación de trabajos académicos, la consulta de recursos lingüísticos en red, la facilidad de compartir documentos de diferentes formatos y la utilización de sitios web para trabajar en el aula. De esta manera, consideramos que se puede reforzar el aprendizaje linguístico del alumnado con proyectos que incorporen las TIC en aspectos en los que hay que profundizar en la reflexión gramatical ya que sería conveniente que los estudiantes compartieran con los compañeros y compañeras las dudas que tienen más habitualmente al escribir, como hemos comprobado en el caso del videoling.

Los proyectos presentados en este estudio cumplen dos condiciones: por un lado, integran objetivos de aprendizaje de la materia y, por otro, tienen relación con el entorno real de los estudiantes. Así pues, se conecta el aprendizaje con el mundo real de una manera más tangible, al tiempo que se desarrolla la autonomía del 
alumnado. Además, al tratarse de proyectos que incluyen un producto final, se obtienen también recursos para incentivar el autoaprendizaje.

Ahora bien, tal y como demuestran estudios como los que hemos mencionado anteriormente (Colás y Pablos, 2004; Barberá y Fuentes, 2012; Méndez Garrido y Delgado García, 2016), estas prácticas no se fomentan ni se apoyan habitualmente en la escuela, donde aún predominan las nociones tradicionales de alfabetización. Por ello, teniendo en cuenta los resultados de este análisis hemos querido poner en evidencia el balance positivo de este tipo de proyecto de innovación docente, que supone la incorporación de recursos TIC para reforzar el aprendizaje lingüístico, la planificación didáctica y la presentación de los productos finales. A su vez, se ofrecen aplicaciones educativas con recursos tecnológicos digitales para mejorar la formación del futuro profesorado de secundaria. De este modo, se pretende atender a la diversidad de intereses y destrezas del alumnado, favorecer un aprendizaje globalizado, introducir la evaluación formativa y darle una aplicación didáctica a la riqueza de recursos que nos ofrecen las herramientas TIC para trabajar proyectos de lengua.

\section{Referencias bibliográficas}

Ballesteros-Regaña, C. (2013). El video en la enseñanza y la formación. En J. Barroso, y J. Cabero (Coords.), Nuevos escenarios digitales: Las tecnologías de la información y la comunicación aplicadas a la formación y desarrollo curricular (pp. 167-186). Madrid: Pirámide.

Barberá, J. P., y Fuentes, M. (2012). Estudios de caso sobre las percepciones de los estudiantes en la inclusión de las TIC en un centro de Educación Secundaria. Profesorado. Revista de currículum y formación del profesorado, 16 (3), 285-305.

Bombini, G., y Martínez, N. (2018). Lectura, escriptura i "noves" tecnologies. Un desafiament a la imaginació didàctica. Articles de Didàctica de la Llengua i la Literatura, 77, 7-13. 
Cabero, J. (2007). La investigación en el ámbito de la Tecnología Educativa. En Cabero, J. (Coord.), Tecnología Educativa (pp. 249-261). Madrid: Mc-Graw-Hill.

Cabero, J., y Barroso, J. M. (2016). El vídeo educativo. En J. Sánchez, J. Ruíz, y M. Gómez (Coords.), Tecnologías de la comunicación y la información aplicadas a la educación (pp. 81-90). Madrid: Síntesis.

Castejón, E., López, C., y Selga, M. (2016). Inclusió digital a l'aula. Barcelona: UOC.

Castelló, M. (2009). Aprender a escribir textos académicos: ¿copistas, escribas, compiladores o escritores? En J. I. Pozo, y M. P. Pérez Echevarría (Coords.), Psicología del aprendizaje universitario: la formación en competencias (pp. 120-133). Madrid: Morata.

Castelló, M. (2014). Los retos actuales de la alfabetización académica: estado de la cuestión y últimas investigacions. Enunciación, 19 (2), 346-365.

Camps, A. (1996). Proyectos de lengua, entre la teoría y la práctica. Cultura y Educación, 2, 43-57.

Camps, A., Guasch, O., y Ruiz Bikandi, U. (2010). La didàctica de la llengua (les llengües) i la literatura. Articles de Didàctica de la Llengua i la Literatura, 52, 81-90.

Carlino, P. (2013). Alfabetización académica diez años después. Revista Mexicana de Investigación Educativa, 57, 355-381.

Castañeda, L., Esteve, F., y Adell, J. (2018). ¿Por qué es necesario repensar la competencia docente para el mundo digital? RED. Revista de Educación a Distancia, 56. Recuperado de http://www.um.es/ead/red/56/castaneda_et_al.pdf.

Churches, A. (2009). Taxonomía de Bloom para la Era Digital. Eduteka. Recuperado de http://eduteka.icesi.edu.co/articulos/TaxonomiaBloomDigital.

Colás, P., y Pablos, J. (2004). La formación del profesorado basada en redes de aprendizaje virtual: aplicación de la técnica DAFO. Teoría de la educación: educación y cultura en la sociedad de la información, 5. Recuperado de http://hdl.handle.net/11162/81306 
Coll, C. (2008). Aprender y enseñar con las TIC: expectativas, realidad y potencialidades. Boletín de la Institución Libre de Enseñanza, 72. Recuperado de http://www.ub.edu/ntae/dcaamtd/Coll_en_Carneiro_Toscano_Diaz_LA STIC2.pdf.

Fernández Campos, A., González Mendizábal, I., y Pérez Gómez, M. (2018). Entorns digitals a les classes de llengua. Canvis tecnològics i innovacions educatives. Articles de Didàctica de la Llengua i la Literatura, 77, 21-28.

Ferrer, M. (2012). L'ensenyament de la gramàtica. Articles de Didàctica de la Llengua i de la Literatura, 57, 87-95.

García García, D. (2014). Creación y edición de vídeo. En F. Trujillo (Coord.), Artefactos digitales. Una escuela digital para la educación de hoy (pp. 114-117). Barcelona: Graó.

Garcia Vidal, P. (2018). Com s'aprenen les llengües en secundària. Creences dels alumnes sobre l'ensenyament-aprenentatge de llengües i possibles implicacions didàctiques. Catarroja: Perifèric.

Garcia Vidal, P., y Martí Climent, A. (2012). Les xarxes socials com a recurs educatiu: Aplicació didàctica en la formació del professorat de Secundària. Articles de Didàctica de la Llengua i la Literatura, 57, 105-113.

Garcia Vidal, P., y Martí Climent, A. (2013). Les TIC en la formació lingüística inicial de mestres. En P. García Pilán, J.F. de Lamo Pastor, y B. Gallardo Paúls (Coords.), Propostes d'Innovació Educativa (pp. 44-53). València: Germania.

Garcia Vidal, P., y Martí Climent, A. (2017). TIC i escriptura acadèmica en el treball per projectes. Articles de Didàctica de la Llengua i la Literatura, 73, 38-42.

Guasch, O. (1997). L'error: una eina per a l'ensenyament. En T. Ribas (Coord.), L'avaluació formativa en l'àrea de llengua (pp. 5166). Barcelona: Graó.

Guasch, O. (2011). Les llengües en l'ensenyament. En A. Camps (Coord.), Llengua catalana $i$ literatura. Complements de formació disciplinària (pp. 25-45). Barcelona: Graó.

Lara, T. (et al.) (2009). La competencia digital en el área de Lengua. Barcelona: Octaedro. 
Marco Común Europeo de Referencia para las Lenguas: aprendizaje, enseñanza, evaluación (2002). Madrid: Instituto Cervantes. Recuperado de http://cvc.cervantes.es/obref/marco

Martí Climent, A., y Garcia Vidal, P. (2014). El treball per projectes amb les TIC a l'àrea de llengua i literatura. Articles de Didàctica de la Llengua $i$ la Literatura, 64, 1-10. Recuperado de http://roderic.uv.es/handle/10550/66506

Martí Climent, A., y Garcia Vidal, P. (2016). Els projectes de llengua en la formació del futur professorat de Secundària. En N. Camps, M. Casas, L. Comajoan, y T. Puntí (Coords.), L'ensenyament del català als territoris de parla catalana. Estat de la qüestió $i$ perspectives de futur (pp. 454-465). Vic: Servei de Publicacions de la Universitat de Vic - Universitat Central de Catalunya.

Méndez Garrido, J. M., y Delgado García, M. (2016). Las TIC en centros de Educación Primaria y Secundaria de Andalucía. Un estudio de casos a partir de buenas prácticas. Digital Education Review, 29.

Ríos, I., y Salvador, V. (2008). L'ensenyament del discurs escrit. Alzira: Bromera.

Rodríguez Gonzalo, C. (2008). La lengua escrita y los proyectos de Trabajo. Propuestas para el aula. Catarroja: Perifèric.

Salmerón, L. (2019). Análisis crítico sobre los efectos de las tecnologías digitales en la lectura y el aprendizaje. Cultura $y$ Educación, $31 \quad$ (3), 472-480. Recuperado de https://www.uv.es/lasalgon/papers/2019_salmeron_delgado.pdf

Sánchez, J., Ruíz, J., y Gómez, M (Coords.) (2016). Tecnologías de la comunicación y la información aplicadas a la educación. Madrid: Síntesis.

Sánchez-Caballé, A., Larraz, V., y González-Martínez, J. (2019). En Gisbert, M, Esteve-González, V., y Lázaro, J. L. (Eds.), ¿Cómo abordar la educación del futuro? Conceptualización, desarrollo y evaluación desde la competencia digital docente (pp. 43-57). Barcelona: Octaedro.

Scolari, C. A. (Ed.) (2018). Adolescentes, medios de comunicación y culturas colaborativas. Aprovechando la competencia 
transmedia de los jóvenes en el aula. Barcelona: Universitat Pompeu Fabra. Recuperado de http://transmedialiteracy.upf.edu/sites/default/files/files/TL_Teens_es.p df.

Trujillo Sáez, F. (2012). Enseñanza basada en proyectos: una propuesta eficaz para el aprendizaje y el desarrollo de las competencias básicas. Revista Eufonía - Didáctica de la Educación Musical, 55, 7-15. Recuperado de http://fernandotrujillo.es/wpcontent/uploads/2012/09/articulo_Eufonia_final.pdf. 